\title{
Assessing the effect of calcium and magnesium \\ UNIVERSIDAD \\ CHILE ions in the structural stability of the protein kinase A through molecular dynamics simulations
}

\author{
Solorza J., Recabarren R. and Alzate-Morales J. \\ E-mail: jsolorza11@alumnos.utalca.cl
}

Centre for Bioinformatics and Molecular Simulation, School of Bioinformatics Engineering, 1 Poniente 1141, Casilla 721, Universidad de Talca, Talca, Chile

\section{Introduction}

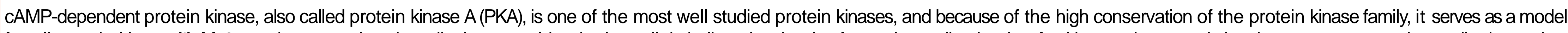

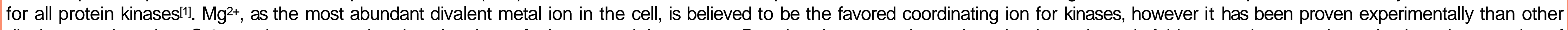

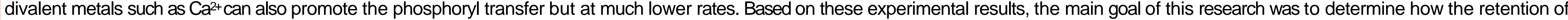
the products occurs and to identify which interactions in the presence of $\mathrm{Ca}^{2+}$ overstabilize the final state of the catalysis in PKA.

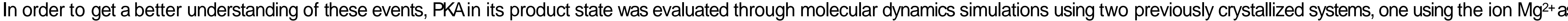

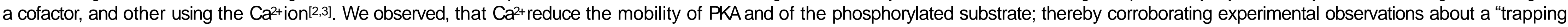

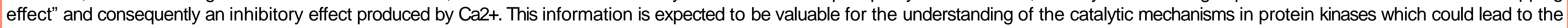
design of more potent inhibitors as well as to understand a possible regulation mechanism exerted by Ca2+onkinases.

\section{Experimental Data}

"Ca+2 increases complex stabilization in the product state."

\begin{tabular}{|lll|c|}
\hline PKA:PKS & $\mathrm{k}_{\mathrm{a}}(1 / \mathrm{Ms})$ & $\mathrm{k}_{\mathrm{d}}(1 / \mathrm{s})$ & \multicolumn{1}{c|}{$\mathrm{K}_{\mathrm{D}}(\mathrm{nM})$} \\
\hline $\mathrm{Mg} \mathrm{g}^{2+} \mathrm{ADP}$ & $1.7 \times 10^{6}$ & $6.5 \times 10^{-2}$ & 38.2 \\
\hline $\mathrm{Ca}^{2+} \mathrm{ADP}$ & $2.3 \times 10^{6}$ & $4.7 \times 10^{-3}$ & 2.0 \\
\hline
\end{tabular}

Table1. SPRanalysis of product dissociation after phosphoryl transfer

\section{$\underline{\text { X-Ray Crystallography Facts }}$}
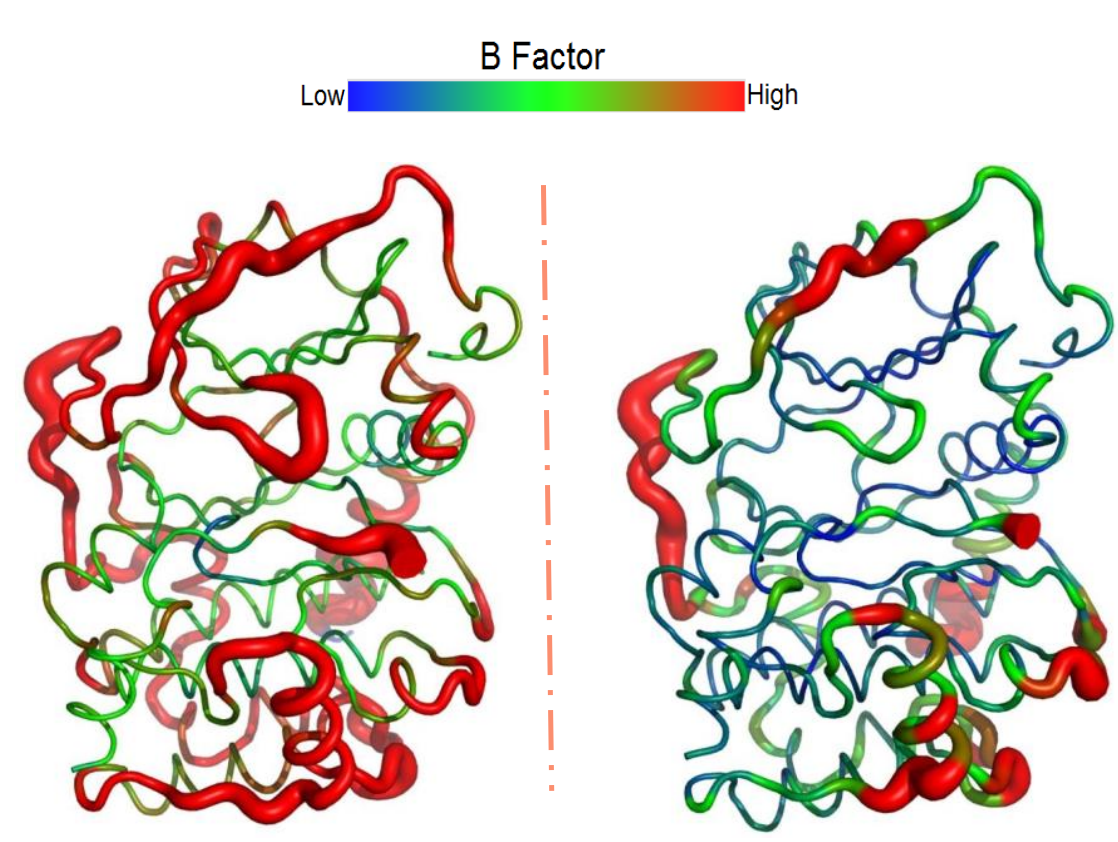

PDBID: 4IAF

PDBID:4IAI
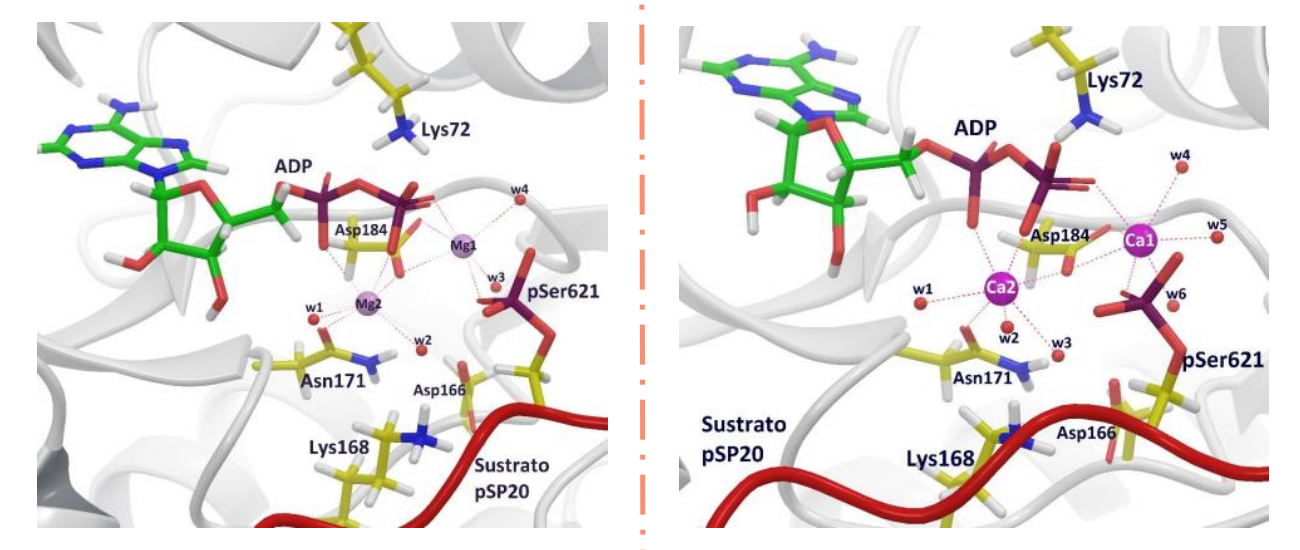

Fig. $1 \beta$-Factor visualization of the ternary complexes showing regions with higher flexibility in red and lower in blue. Coordination spheres are shown for each ion in the

\section{Materials \& Methods}

Crystal structures with PDB codes 4IAF and 4IAI were used as starting points. Protein preparation was performed with the Protein Preparation Wizard tool implemented in Maestro4. Molecular dynamics simulations were carried out with the software Amber $14^{5}$ and the force field ff99SB 6 . The systems were firstly energy minimized and equilibrated by short MD simulations in the NVT and NPT ensembles. Temperature and pressure were kept fixed at $300 \mathrm{~K}$ and 1 atm, respectively. Production runs were performed for 100 ns in the NPT ensemble which were used for subsequent an in the All analysis Were caried out with the tool cpptraj analysis. All analysis were carried out with the tool cpptraj of Amber 14 and VMD plugins. VMD was used for the display of the molecular dynamics simulations.

\section{Results}

\section{Distances atoms key}

A)
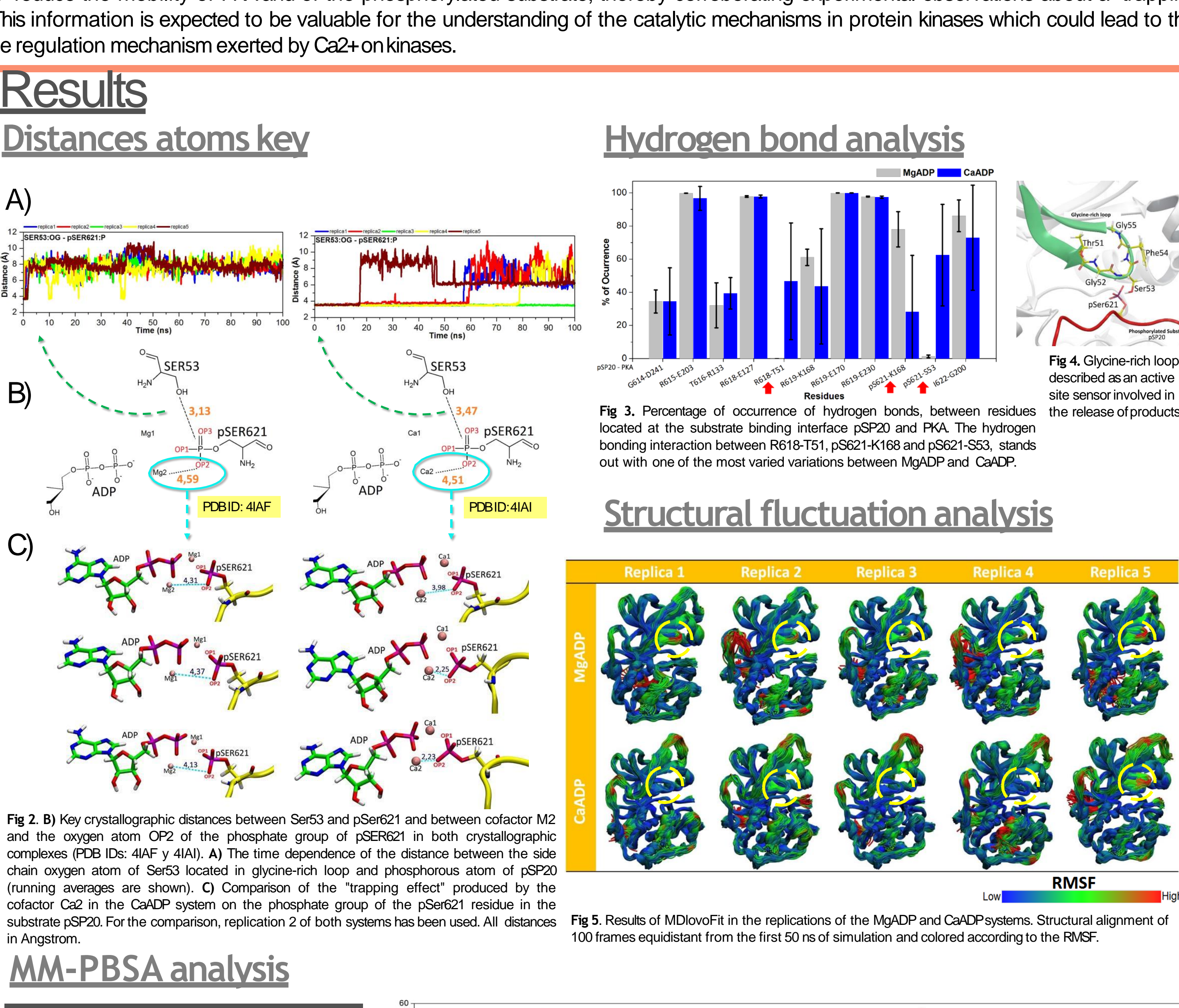

B)
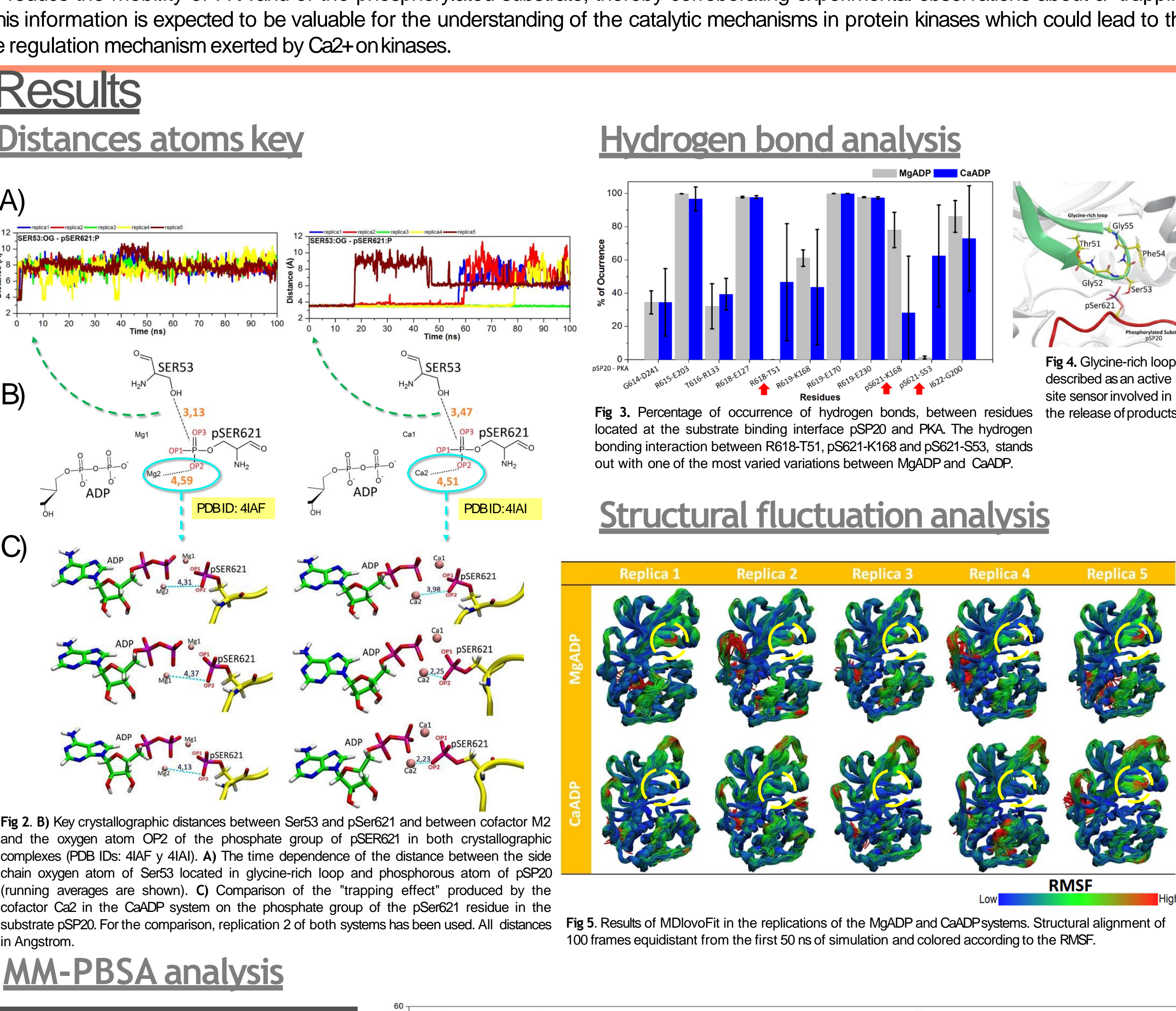

C)

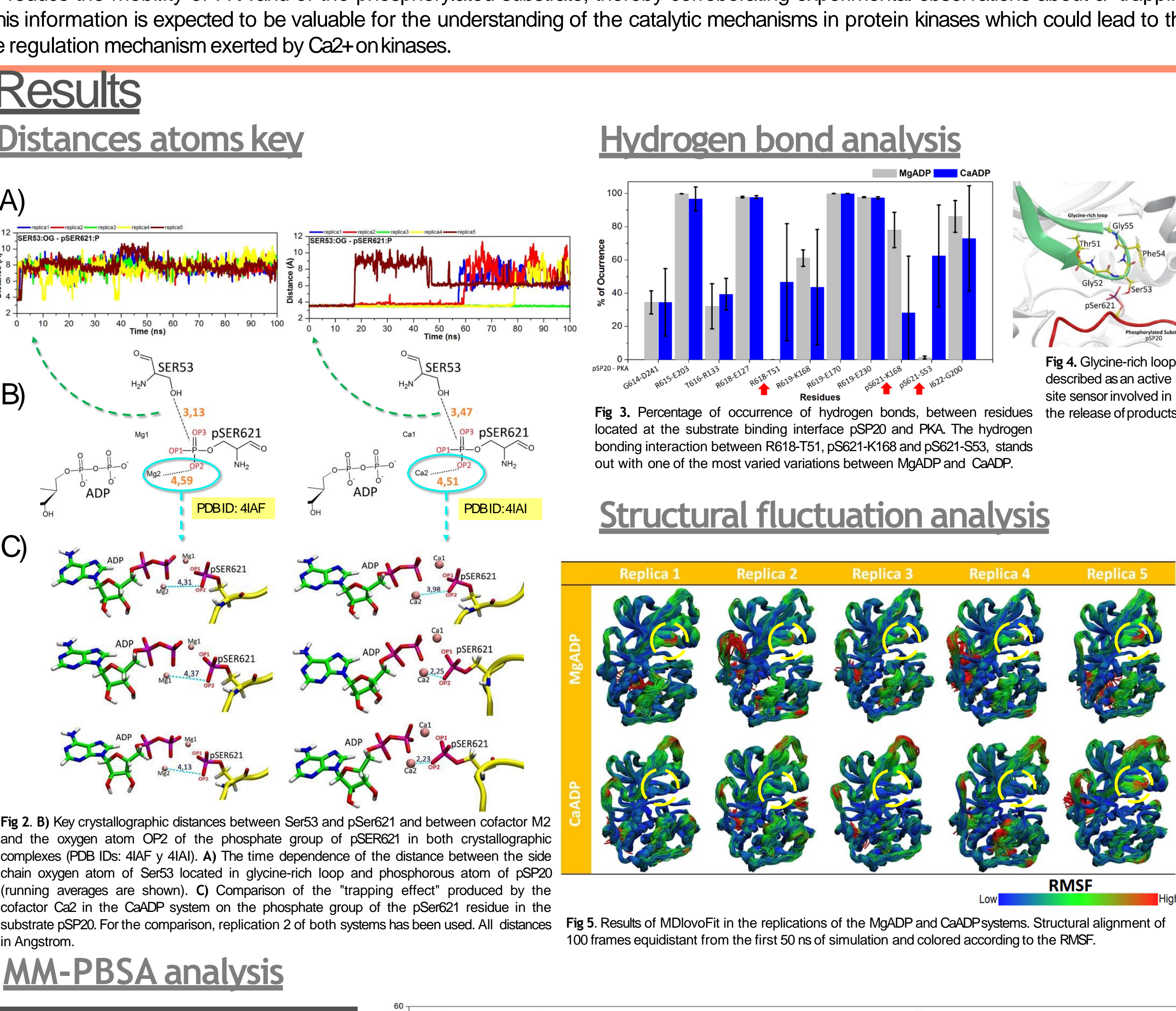

Fig 2. B) Key crystallographic distances between Ser53 and pSer621 and between cofactor M2 and the oxygen atom OP2 of the phosphate group of pSER621 in both crystallographic complexes (PDB IDs: 4IAF y 4IAI). A) The time dependence of the distance between the side chain oxygen atom of Ser53 located in glycine-rich loop and phosphorous atom of pSP20
(running averages are shown). C) Comparison of the "trapping effect" produced by the cofactor 22 in the $\mathrm{CaAP}$ systom on the phosphate group of the pSer621 residue in the in Angstrom.

\section{MM-PBSA analvsis}

\section{References}

